\title{
L-DOPA-induced Dyskinesia is Associated with Regional Increase of Striatal Dynorphin Peptides as Elucidated by Imaging Mass Spectrometry ${ }^{\star_{\text {[S }}}$
}

\author{
Jörg Hanriederłף ${ }^{\star *}$, Anna Ljungdahl¥ ${ }^{\star *}$, Maria Fälth§, Sofie Eriksson Mammoł, \\ Jonas Bergquistๆ, and Malin Andersson‡||
}

Opioid peptides are involved in various pathophysiological processes, including algesia, epilepsy, and drug dependence. A strong association between L-DOPA-induced dyskinesia (LID) and elevated prodynorphin mRNA levels has been established in both patients and in animal models of Parkinson's disease, but to date the endogenous prodynorphin peptide products have not been determined. Here, matrix-assisted laser desorption ionization (MALDI) imaging mass spectrometry (IMS) was used for characterization, localization, and relative quantification of striatal neuropeptides in a rat model of LID in Parkinson's disease. MALDI IMS has the unique advantage of high sensitivity and high molecular specificity, allowing comprehensive detection of multiple molecular species in a single tissue section. Indeed, several dynorphins and enkephalins could be detected in the present study, including dynorphin A(1-8), dynorphin B, $\alpha$-neoendorphin, MetEnkRF, MetEnkRGL, PEnk (198-209, 219229). IMS analysis revealed elevated levels of dynorphin $B$, $\alpha$-neoendorphin, substance P, and PEnk (220-229) in the dorsolateral striatum of high-dyskinetic animals compared with low-dyskinetic and lesion-only control rats. Furthermore, the peak-intensities of the prodynorphin derived peptides, dynorphin B and $\alpha$-neoendorphin, were strongly and positively correlated with LID severity. Interestingly, these LID associated dynorphin peptides are not those with high affinity to $\kappa$ opioid receptors, but are known to bind and activate also $\mu$ - and $\Delta$-opioid receptors. In addition, the peak intensities of a novel endogenous metabolite of $\alpha$-neoendorphin lacking the $\mathrm{N}$-terminal tyrosine correlated positively with dyskinesia severity. MALDI IMS of striatal sections from Pdyn knockout mice verified the identity of fully processed dynorphin peptides

From the $\ddagger$ Department of Pharmaceutical Biosciences, Drug Safety and Toxicology, Uppsala University, Uppsala, Sweden; §Division of Molecular Genetics, Cancer Genome Research, German Cancer Research Centre (DKFZ), Heidelberg, Germany; IDepartment of Physical and Analytical Chemistry, Analytical Chemistry, Uppsala University, Uppsala, Sweden

Received March 5, 2011, and in revised form, June 27, 2011

Published, MCP Papers in Press, July 6, 2011, DOI 10.1074/ mcp.M111.009308 and the presence of endogenous des-tyrosine $\alpha$-neoendorphin. Des-tyrosine dynorphins display reduced opioid receptor binding and this points to possible novel nonopioid receptor mediated changes in the striatum of dyskinetic rats. Because des-tyrosine dynorphins can only be detected by mass spectrometry, as no antibodies are available, these findings highlight the importance of MALDI IMS analysis for the study of molecular dynamics in neurological diseases. Molecular \& Cellular Proteomics 10: 10.1074/mcp.M111.009308, 1-14, 2011.

The dopamine precursor L-3,4-dihydroxy-phenylalanine $(L-D O P A)^{1}$ is still the most effective drug for symptomatic treatment of Parkinson's disease (PD). However L-DOPA pharmacotherapy is accompanied by debilitating motor complications including L-DOPA-induced dyskinesia (LID). Evidence point to a fundamental disturbance of the basal ganglia function induced by the loss of dopamine (DA) and that leads to the facilitation of dyskinogenesis in PD (1).

L-DOPA-induced dyskinesia in patients with PD has been linked to elevated levels of preproenkephalin (PPE or PPE-A) and prodynorphin (PDyn or PPE-B) mRNA in the striatum (2-4). Similarly increased striatal levels of PPE mRNA, but even more pronounced PDyn mRNA levels have been reported in DA-denervated animal models of LID, including primates, monkeys, and rodents (5-10).

To our knowledge no study has assessed changes in neuroactive opioid levels in relation to LID in PD, despite numer-

${ }^{1}$ The abbreviations used are: L-DOPA, L-3,4-dihydroxy-phenylalanine; DHB, 2,5-dihydroxybenzoic acid; 6-OHDA, 6-hydroxydopamine; AIM, Abnormal involuntary movements; aNeo, Alpha-neoendorphin; CPu, Caudate putamen; DA, Dopamine; DynB, Dynorphin B; IMS, Imaging mass spectrometry; KOPr, MOPr, DOPr, kappa -, mu -, delta-opioid receptor; LID, L-DOPA-induced dyskinesia; LC-ESI FTICR MS, Liquid chromatography-electrospray Fourier transform mass spectrometry; MALDI, Matrix-assisted laser desorption/ionization; PD, Parkinson's disease; PPE, Preproenkephalin; PDyn, Prodynorphin; PEnk, Proenkephalin; RIA, Radioimmunoassay; ROI, Regions of interest; SAM, Statistical analysis of microarray data; SP, Substance $P$. 
ous studies on opioid precursor mRNA (11). In fact, little is known about which distinct opiod precursor-derived peptide products are involved in pathophysiologic mechanisms underlying LID. PPE mRNA can be processed into e.g. enkephalin, leu-enkephalin (Leu-Enk), met-enkephalin (Met-Enk), and enkephalin-containing peptide $\mathrm{E}$ and peptide $\mathrm{F}$, whereas PDyn mRNA can be processed into several different dynorphins; including dynorphin A (DynA), dynorphin B (DynB), $\alpha / \beta$-neoendorphin (a/bNeo), and Leu-Enk $(12,13)$.

So far only immunohistochemistry and radioimmunoassay (RIA) have been used to study changes in levels of specific endogenous opioid peptides in the human parkinsonian brain. In the post mortem PD striatum, Met-Enk and Leu-Enk peptide levels were decreased and DynA (1-8; 1-13 and/or 1-17) peptide levels remained unchanged, however the presence or severity of LID was not reported in these early studies (14-16). In addition, clinical and preclinical studies of the effects of opioid antagonists on LID have often displayed conflicting results (11). For example, nonselective opiate antagonists have been associated with both ailing and worsening of LID in PD patients and animal models (10, 17-20).

In the rat model of LID and PD, the expression of PDyn mRNA correlates highly with the level of FosB-related transcription factors in medium-sized spiny neurons of the dorsolateral striatum of animals displaying axial, limb and orolingual dyskinesia (21). In addition, prodynorphin mRNA and FosB-related protein levels were both elevated in the medial striatum in animals exhibiting rotational locomotive activity (21). Because of this distinct regional protein and peptide expression patterns related to behavior it is important to study molecular correlates of LID using advanced imaging techniques that offer high molecular specificity. In the present study we investigated region-specific expression of striatal neuropeptides in the rat model of LID and PD using matrixassisted laser desorption and ionization (MALDI) imaging mass spectrometry (IMS; Fig. 1A). MALDI IMS is an emerging technique of great potential for spatial profiling of molecular species in biological tissue samples $(22,23)$. Mass spectrometric molecular imaging is advantageous in that it allows for the detection of many different analytes simultaneously in native tissue sections. In order to detect and image neuropeptides, 2,5-dihydroxybenzoic acid was used as a MALDI matrix and the sections were analyzed on a MALDI-TOF operating in reflector mode $(24,25)$. Several groups have analyzed single brain sections to obtain information of distribution patterns of endogenous neuropeptides or to describe technical improvements (26-31). However to our knowledge, this is the first report of a MALDI IMS-based statistical interrogation of pathophysiological changes in endogenous neuropeptide levels in the mammalian brain.

\section{EXPERIMENTAL PROCEDURES}

Reagents-Acetonitrile, methanol, acetic acid, ammonium acetate, ammonium bicarbonate, ammonium-dihydrogen-phosphate
$\left(\mathrm{NH}_{4} \mathrm{H}_{2} \mathrm{PO}_{4}\right)$, formic acid and ethanol was of pro-analysis grade and purchased from Merck (Darmstadt, Germany). Trifluoroacetic acid was obtained from Sigma Aldrich (St. Louis, MO). Water was purified with a Milli-Q (Millipore, Bedford, MA) purification system. 2,5-dihydroxy benzoic acid (DHB), peptide and protein calibration standards were purchased from Bruker Daltonics (Bremen, Germany).

Pdyn Knockout Mice-Pdyn ${ }^{-1-}$ mice were originally obtained by targeted deletion of the coding exons of the prodynorphin gene and bred into a 129SvEv-Tac background as described (32). Animals were housed in groups of up to four per cage with food and water ad libitum in a room with a 12:12 h light:dark cycle. DNA from each animal was extracted for subsequent genotyping to confirm the identity of the Pdyn locus as described (32). Brain tissues were isolated from two male and one female Pdyn knockout mice after overexposure to halothane and cervical dislocation, and frozen in liquid nitrogen.

\section{Experimental Model of Parkinson's Disease}

Unilateral Lesion Surgery-Female Sprague-Dawley rats (B\&K, Sollentuna, Sweden), weighing 210 to $250 \mathrm{~g}$ at the time of surgery were housed four to a cage in a room with a 12-h light/dark cycle with food and water ad libitum. The experiments were approved by the Uppsala animal ethical committee and followed the guidelines of Swedish legislation on animal experimentation (Animal Welfare Act SFS1998: 56) and European Union legislation (Convention ETS123 and Directive $86 / 609 /$ EEC). Rats anesthetized with isoflurane (2.5\%, Apoteksbolaget $A B$, Stockholm, Sweden) received stereotaxic injections of 6-hydroxydopamine hydrochloride (6-OHDA- $\mathrm{HCl})$ into the right ascending DA fiber bundle, as described previously (5). Briefly, 6-OHDA-HCl (Sigma Aldrich) was dissolved in $0.02 \%$ ascorbate acid in saline at a concentration of $3.6 \mu \mathrm{g} / \mu \mathrm{l}$ and injected at the following coordinates in millimeters relative to the bregma and the dural surface (33): (1) A, -4.4 ; L, 1.2; V, 7.8; tooth bar at -2.3 (7.5 $\mu \mathrm{g}$ deposit); (2) A, -4.0; L, $0.75 ; \mathrm{V}, 8.0$; tooth bar at +3.4 ( $6 \mu \mathrm{g}$ deposit). 6 -OHDA infusions were performed at $1 \mu \mathrm{l} / \mathrm{min}$ using a $10 \mu \mathrm{l} \mathrm{Hamilton}$ syringe. For postoperative analgesia the rats were given Rimadyl (5 mg/kg, s.c., Apoteksbolaget $\mathrm{AB}$ ).

L-DOPA Treatment and Behavioral Analysis-Forelimb use asymmetry was assessed using the cylinder test screening at 3 weeks post-6-OHDA lesion (34). Briefly, rats were placed in a glass-cylinder in a new environment and their forelimb touches (summing up to 20) were counted as they were rearing to explore the new environment. Only rats that used their contralateral forelimb less than $30 \%$ of the time were included in this study, corresponding to approximately $>70 \%$ striatal DA depletion (35). L-DOPA treatment and recording of dyskinesia started the day after the limb-asymmetry test. L-DOPA and the peripheral DOPA-decarboxylase inhibitor, benserazide- $\mathrm{HCl}$, were purchased from Sigma. At 3 weeks post lesion, rats started to receive single daily intraperitoneal injections of $8 \mathrm{mg} / \mathrm{kg}$ L-DOPA plus 15 $\mathrm{mg} / \mathrm{kg}$ benserazide, or physiological saline ("lesion-only" controls). L-DOPA-induced abnormal involuntary movements (AIMs) were recorded every other day according to Cenci et al. (1998) (5). Briefly, rats were observed individually every 20th minute (1-min monitoring periods) during the $3 \mathrm{~h}$, which followed a daily L-DOPA dose. Repetitive movements which affected the side of the body contralateral to the lesion, and could not be ascribed to any normal behavioral pattern, were classified into four subtypes: locomotive AIMs, i.e. increased locomotion with contralateral side bias; axial dystonia, i.e. contralateral twisted posturing of the neck and upper body; orolingual AIMs, i.e. stereotyped jaw movements and contralateral tongue protrusion; and forelimb dyskinesia, i.e. repetitive jerks of the contralateral forelimb, sometimes combined with grabbing movements of the paw. Each rat was scored on a severity scale from 0 to 4 on each of these four subtypes; the theoretical maximum score that could be reached by a rat in one session was thus 144 (maximum score per 
monitoring period $=16$; number of monitoring periods per session $=$ 9). Statistical analysis was performed by means of nonparametric Kuskal Wallis ANOVA in Origin (version 8.1, Originlab, Northhampton, MA, USA). At 60 min after the last L-DOPA (or saline) injection, rats were deeply anesthetized with isoflurane and killed by decapitation. The brains were rapidly extracted and were frozen on dry ice and stored at $-80^{\circ} \mathrm{C}$.

MALDI Imaging-Striatal brain sections $(12 \mu \mathrm{m})$ were cut on a cryostat microtome (Microm, Heidelberg, Germany) and thaw mounted on conductive glass slides suitable for MALDI IMS analysis (Bruker Daltonics). Prior to matrix application, the sections were dried in a vacuum desiccator for $1 \mathrm{~h}$. In order to fixate tissue and remove salts that interfere with MALDI ionization, the sections were washed with $70 \%$ ethanol for $10 \mathrm{~s}$, followed by $95 \%$ ethanol twice for $10 \mathrm{~s}$ and dried in a vacuum desiccator. DHB matrix $(50 \mathrm{mg} / \mathrm{ml}$ DHB in $50 \%$ methanol, $15 \mathrm{~mm}$ ammonium acetate, $0.3 \%$ trifluoroacetic acid) was applied with a spatial resolution of $300 \times 300 \mu \mathrm{m}$ across the brain section using a chemical inkjet printer (Chip 1000, Shimadzu). A volume of $500 \mathrm{pL}$ ( 5 drops) per spot during each pass and 12 passes of matrix application were applied. Mass spectra were acquired on an Ultraflex II MALDI TOF/TOF instrument (Bruker Daltonics) running in reflector positive mode. A mass range of 500-3500 Da was analyzed with a laser frequency of $100 \mathrm{~Hz}$ and a laser focus set to large. A total sum of 600 shots per spot was acquired in steps of 50 shots in a random pattern. Data sequence preparation, MS acquisition and visualization was performed using the FlexImaging and FlexControl software (version 2.0, Bruker Daltonics).

Data Evaluation-As an initial step of data analysis, regions of interest (ROI) were assigned for each brain section. These ROI comprised the lateral and medial caudate putamen $(\mathrm{CPu})$ on both the lesioned and intact side of the section (see Fig 1D). All mass spectra were batch processed by means of baseline subtraction and external calibration before exported as single ascii files using the Flex Analysis Software (version 3.0, Bruker Daltonics). The ascii files were imported in the PDS software (version 2.2.2, Medicwave, Halmstad, Sweden) software for data post-processing by means of normalization and peak analysis. This included TIC normalization, peak picking $(\mathrm{S} / \mathrm{N}>3)$ and binning analysis for determining the bin borders and final rebinning for extracting peak area values (area under curve, AUC). Peak area values were evaluated in Excel (v. 2007) using the "Statistical Analysis of Microarray data" (SAM) tool for grouped unpaired statistical analysis (non parametric test) (36). The SAM tool was originally developed for microarray analysis and allows comprehensive and unbiased analysis of significant changes in abundance levels between two groups. Further analysis of single peptides and comparisons between three groups was performed with nonparametric ANOVA (Kuskal Wallis) followed by post hoc analysis (Tukey HSD test). The null hypothesis was rejected at $p<0.05$.

Immunohistochemistry-Double-antigen immunohistochemistry was performed using goat anti-FosB (Santa Cruz Biotechnology, Santa Cruz, California) diluted at 1:200 and rabbit anti-dynorphin B diluted at $1: 500(37,38)$ as primary antibodies. Fluorescent secondary antibodies were used for visualization (anti-rabbit-Alexa Fluor 488; 1:200, Invitrogen, Carlsbad, CA or anti-goat-RRX, 1:200, Jackson ImmunoResearch, West Grove, PA). Cell nuclei were visualized by DAPI (4',6-diamidino-2-phenylindole, Sigma-Aldrich).

Relative quantifications of striatal FosB- and nigral TH-immunopositive cells were performed using rabbit-anti-FosB $(1: 10,000$, Santa Cruz Biotechnology) and mouse-anti-TH antiserum (1:1000, MAB318, Millipore, CA) and employing a standard peroxidase-based method with 3,3'-diamobenzidine as a chromogen according to the manufacturer's instructions (R.T.U VECTASTAIN Universal Quick Kit and ImmPACT DAB, Vector Laboratories, Burlingame, CA). Counts of $\mathrm{TH}$-immunopositive cells at three rostrocaudal levels of $\mathrm{SN}$ were carried out by a blinded investigator and the percentage remaining DA cells in the lesion side were calculated in relation to the intact side of the rat brain. The number of FosB-immunoreactive nuclei was quantified in the dorsolateral striatum of high $(n=6)$ and low dyskinetic animals $(n=8)$ using ImageJ (NIH, Bethesda, MD). Statistical analysis was performed by means of Kruskal Wallis ANOVA in Origin as well as simple regression analyses in MS excel.

\section{Peptide Identification}

Peptide Extraction from Tissue Homogenates - Striatal opioid peptides were characterized using a modified protocol based on strong cation exchange prefractionation as described previously $(39,40)$. Briefly, frozen rat brain was mounted on a cryostat chuck at $-20^{\circ} \mathrm{C}$, the cortex and corpus callosum removed and the nucleus accumbens (NAc) was separated from the caudate putamen by a thin cut from the most ventral point of the lateral ventricle to the most ventral point of the external capsule. Tissue sections from the CPu and NAc $(20 \mu \mathrm{m}$, $n=50$ and 50 , respectively) were thaw-mounted on separate superfrost glass slides (Thermo Scientific, Waltham, MA). Off tissue extraction was performed by repeated addition and collection of $300 \mathrm{mi}-$ croliter $5 \%$ acetonitrile, $0.1 \%$ trifluoroacetic acid. The combined extracts were centrifuged at $5000 \times g$ for $10 \mathrm{~min}$. The supernatant was applied to small ion exchange columns (SP C25 Sephadex, GE Healthcare, Uppsala, Sweden), and eluted stepwise with buffers containing pyridine in $0.1 \%$ formic acid $(0,30,70$, and $100 \%$ pyridine). The fractions were dried down under reduced pressure using a speedvac system (ThermoSavant, Waltham, MA) and stored at $4{ }^{\circ} \mathrm{C}$. Prior to further analysis the individual fractions were reconstituted in $50 \mu \mathrm{l} \mathrm{1 \%} \mathrm{HAc}$ and analyzed by means of nanoscale-liquid chromatography coupled on-line to electrospray Fourier transform mass spectrometry (LC-ESI FTICR MS).

LC-ESI FTICR MS-LC-ESI FTICR MS was performed on an Agilent 1100 nanoflow system (Agilent Technologies, Santa Clara, CA) hyphenated to a LTQ-FT 7.0 T (Thermo Scientific). A volume of $5 \mu \mathrm{l}$ from the reconstituted SCX fraction was injected automatically and loaded onto a self prepared C18 PicoFrit column $(75 \mu \mathrm{m} \mathrm{ID} / 15 \mu \mathrm{m}$ tip ID, NewObjective, Woburn, MA) packed directly inside the electrospray needle tip using specially designed nanospray emitter tips. A water/formic acid/acetonitrile solvent system was used where solvent A was $0.1 \%$ formic acid and solvent B was $100 \%$ acetonitrile, $0.1 \%$ formic acid. Gradient elution was performed from $0 \%$ B for 10 min, the from $0 \%$ B to $50 \%$ B for 100 min, then from $50 \%$ B to $90 \%$ B for 5 min, then $90 \% \mathrm{~B}$ for $5 \mathrm{~min}$ and finally from $90 \%$ B back to $0 \%$ B for 5 min. Peptide elution was followed by ESI FTICR MS and tandem mass spectrometry (MS/MS) for peptide sequencing controlled by the Xcalibur software (version 2.0 SR2, Thermo Scientific). Fullscan spectra were acquired at high resolution $(\mathrm{FWHM}=100000)$ using the FT analyzer. Data dependant acquisition was applied for MS/MS precursor selection, where the five most intense mass peaks were subjected to subsequent isolation and collision-induced fragmentation in the ion trap. Acquired raw data were exported to an mgf file using an inhouse written script $(\mathrm{C}++)$.

Peptide Sequence Identification-The annotated fragment spectra were subjected to database search using, the Mascot search engine (version 2.2, Matrix Science, London, UK) (1-43). Mascot searches were performed against two databases containing sequences of known rat neuropeptides (SwePep peptides, 245 peptide entries, www.swepep.org,) and neuropeptide precursor proteins (Swepep precursor, 123 protein entries) using the following specifications: mass tolerance (MS: $\pm 20 \mathrm{ppm}, \mathrm{MS} / \mathrm{MS}: \pm 1.2 \mathrm{Da}$ ) enzyme (none), fixed modifications (none), variable modifications (deamidation, Cterm. amidation, oxidation of Met), max. precursor charge $(4+)$ and instrument (ESI-TRAP). Peptide matches with a score above the confidence threshold $(p<0.05)$ were considered to be a significant 


\section{Dynorphin Peptide Alterations in L-DOPA-induced Dyskinesia}

A
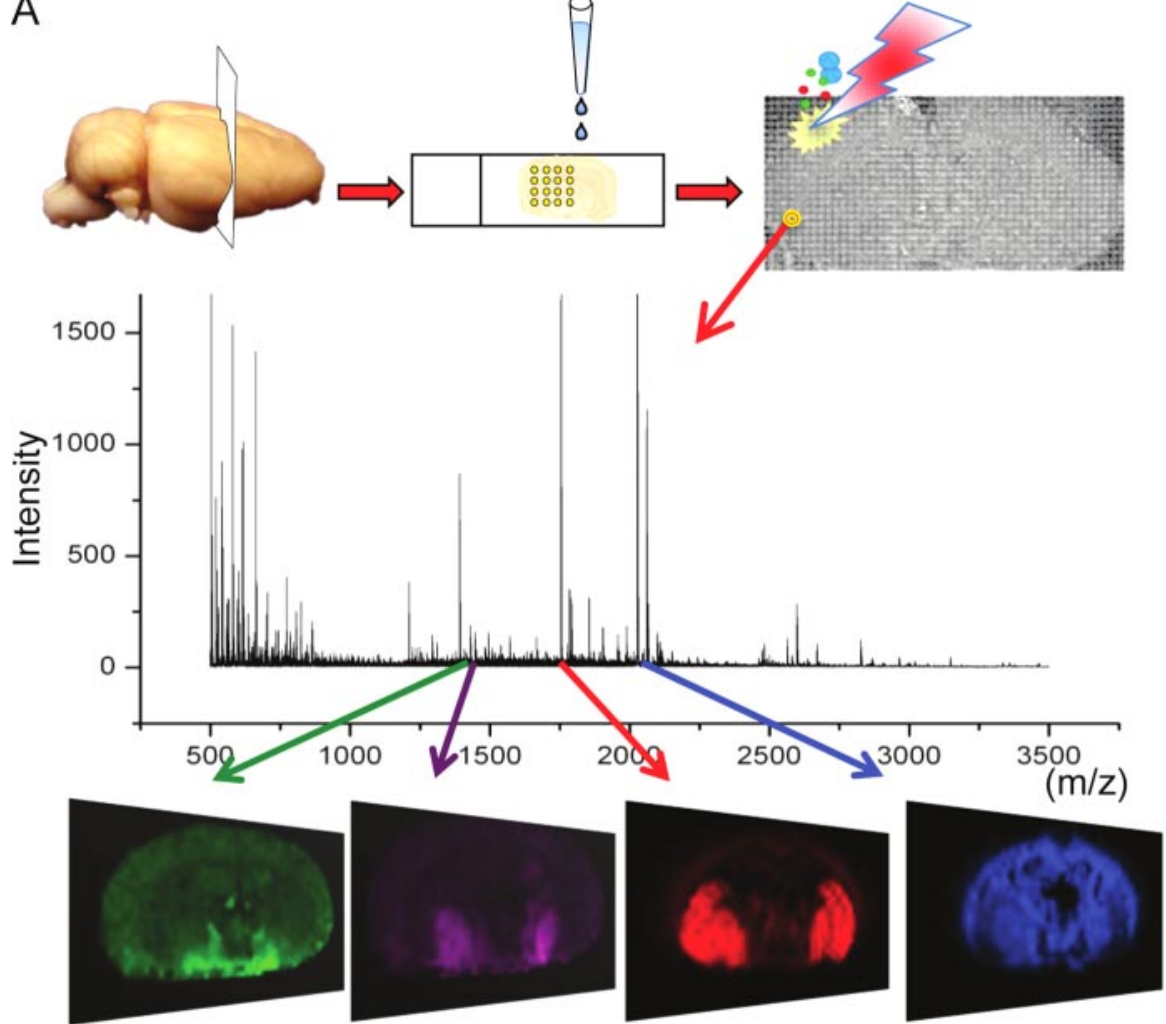

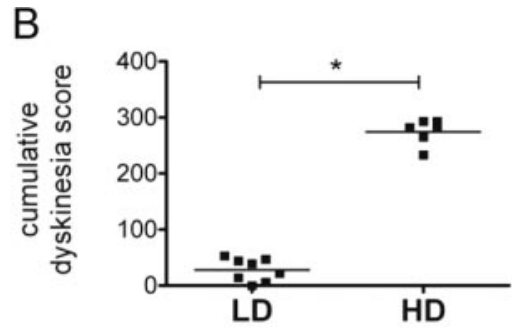

C

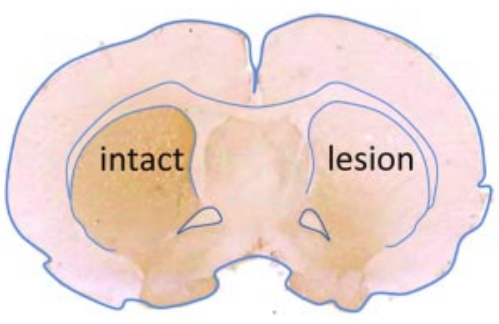

FIG. 1. MALDI imaging mass spectrometry. A, Experimental workflow: Sections of frozen rat brains are thaw-mounted onto MALDI compatible glass slides. MALDI matrix solution is applied as discrete spots in a quadratic pattern and mass spectra from individual matrix deposits are acquired by means of MALDI TOF MS. The intensity distribution of individual peaks is visualized using user-defined colors, here in green SP; in violet PEnk 220-229; in red PEP-19 fragment; in blue MBP fragment. $B$, Behavioral analysis: High dyskinetic (HD) animals accumulated a 10-fold higher dyskinesia score than low dyskinetic (LD) animals. C, Unilateral DA denervation: Unilateral 6-OHDA-lesion model of experimental PD results in selective dopamine-denervation of striatum, revealed by a loss of tyrosine hydroxylase immunoreactivity. $D$, Regional analysis: Several markers were visualized to delineate anatomical features, including myelin basic protein ( $m / z$ 2028; b/ue) that is predominantly abundant in the corpus callosum, and a PEP-19 fragment $(\mathrm{m} / \mathrm{z} 1755$; red) that is exclusively observed in the striatum. The striatum was divided into a dorsomedial (DM) and a dorsolateral (DL) regions of interest (ROI) for MS analysis. * $p<0.01$. Scale bar $2.5 \mathrm{~mm}$.

hit. The false positive identification rate (FPR) was estimated by searching the data against a decoy database, where the FPR threshold was set to $<1 \%$.

\section{RESULTS}

Chronic Intermittent L-DOPA-Treatment Results in Both High-and Low-dyskinetic Animals-Dyskinesia ratings were conducted every other day during 15 days of L-DOPA treatment with once daily injections of a relative low dose L-DOPA (8 $\mathrm{mg} / \mathrm{kg} \mathrm{L-DOPA}$ and $15 \mathrm{mg} / \mathrm{kg}$ benserazide; see supplemental Fig. S1 for experimental workflow). Severe dyskinesia was observed in six animals (high dyskinetic, HD group) and 10 animals remained low dyskinetic until the end of the treatment period (LD group). The HD group displayed a 10fold higher cumulative axial, limb, and orolingual dyskinesia score compared with the LD group $(p<0.01$ HD versus LD group) (Fig. 1B). Only three animals displayed low to moderate levels of spontaneous locomotive and rotational activity in combination with axial dystonia. The extent of 6-OHDA-lesion was equal in all groups, including the lesion control group (LC, $n=4$ ), with less than $10 \%$ of the number of $\mathrm{TH}$-immunopo- sitive cells remaining on the lesion side compared with the intact control substantia nigra (mean \pm S.E.; LC group $7.75 \% \pm 1.65$, LD group $8.97 \% \pm 2.23$, and HD group $10.5 \%$ $\pm 2.93)$. The DA-denervated side of the striatum displayed a typical loss of DAergic innervation, as visualized by $\mathrm{TH}$-immunochemistry (Fig. 1C).

MALDI Imaging MS and Identification of NeuropeptidesMALDI IMS experiments were performed in triplicates resulting in three data sets each comprising striatal sections from 18 animals (sections of two LD animals displayed severe freeze artifacts, generated low signal-to-noise spectra and were excluded from further analysis). The MS analysis revealed more than 1000 peaks, with the equivalent of about three peaks/peptide, resulting in the detection of 350 monoisotopic peptide peaks in mass spectra acquired from the striatal ROI, comprising the dorsolateral (DL) and dorsomedial part (DM) of the lesioned and intact striatum, respectively (Fig. 1D). For each brain section the markers for myelin basic protein ( $\mathrm{m} / \mathrm{z}$ 2028; Fig $1 D$ ) that is predominantly abundant in the corpus callosum and a fragment of PEP-19 $(\mathrm{m} / \mathrm{z}$ 
TABLE I

Sequence verified striatal neuropeptides. The peptides were detected by means of MALDI IMS and sequence verified using off tissue LC- FTICR ESI-MS/MS

\begin{tabular}{|c|c|c|c|c|c|c|c|c|}
\hline \multirow{2}{*}{ Entry $^{a}$} & \multirow{2}{*}{ Accession $^{a}$} & \multirow{2}{*}{ Peptide } & \multirow{2}{*}{$z^{b}$} & \multirow{2}{*}{ Sequence $^{a}$} & \multicolumn{2}{|c|}{$\operatorname{mass}[\mathrm{M}+\mathrm{H}]^{+c}$} & \multirow{2}{*}{$\Delta \mathrm{m}(\mathrm{ppm})$} & \multirow{2}{*}{ Score } \\
\hline & & & & & theoretical & observed & & \\
\hline PENK_RAT & P04094 & Met-enkephalin-Arg & 2 & YGGFMR & 730.33 & 730.33 & 2 & 35 \\
\hline PDYN_RAT & P06300 & Dynorphin A (2-8) & 2 & GGFLRRI & 818.49 & 818.49 & 7 & 22 \\
\hline PDYN RAT & P06300 & Dynorphin A (10-17) & 2 & PKLKWDNQ & 1028.55 & 1028.55 & 1 & 45 \\
\hline PDYN RAT & P06300 & alpha-neoendorphin (2-10) & 2,3 & GGFLRKYPK & 1065.61 & 1065.61 & 6 & 23 \\
\hline PDYN_RAT & P06300 & alpha-neoendorphin & 2,3 & YGGFLRKYPK & 1228.67 & 1228.68 & 9 & 28 \\
\hline PENK RAT & P04094 & Proenkephalin (219-229) & 2 & VGRPEWWMDYQ & 1466.64 & 1466.64 & 1 & 66 \\
\hline PDYN_RAT & P06300 & Dynorphin B & 3 & YGGFLRRQFKVVT & 1570.88 & 1570.89 & 6 & 11 \\
\hline
\end{tabular}

a Peptide database entry, sequence and accession number were obtained from the uniprot knowledgebase (www.uniprot.org). Marked sequences $(*)$ indicate C-term. amidation.

${ }^{b}$ Charge state $(z)$ of the peptide as detected by LC-MS/MS.

${ }^{c}$ The peptide mass to charge $(\mathrm{m} / \mathrm{z})$ is given for singly charged species. The observed masses refer to the MALDI imaging experiments.

${ }^{d}$ Mascot MS/MS ion scores obtained for the respective peptide.

1755; Fig 1D) that is exclusively observed in the striatum were visualized in Flexlmaging together with the photomicrograph of the spotted section. The striatum from the ventral tip of the lateral ventricles, following the corpus callosum to the most ventral point of capsula externa delineated the upper border of the striatum, and a straight line between the two most ventral points separated the caudate putamen from the $n$. accumbens. This ventral border was bisected by a perpendicular line dividing the ROI into the DM and DL part. Only results consistent in all three replicate experiments are presented here $(p<0.05$, HD versus LD and HD versus LC, using $<1 \%$ false discovery rate). High mass accuracy Fourier transform ion cyclotron (FT-ICR) mass spectrometry in conjunction with collision induced fragmentation of striatal peptide extracts, unequivocally confirmed the identity of several neuropeptides, including dynorphin B (DynB, $\mathrm{m} / \mathrm{z}$ 1570.88), $\alpha$-neoendorphin (aNeo, $\mathrm{m} / \mathrm{z}$ 1228.68), substance P (SP, $\mathrm{m} / \mathrm{z}$ 1347.7), as well as Met-Enk-Arg ( $\mathrm{m} / \mathrm{z}$ 730.3), Met-Enk-ArgPhe ( $\mathrm{m} / \mathrm{z}$ 877.4), Met-Enk-Arg-Gly-Leu ( $\mathrm{m} / \mathrm{z}$ 900.4), PEnk (220-229; $\mathrm{m} / \mathrm{z}$ 1367.5), PEnk (198-209; $\mathrm{m} / \mathrm{z}$ 1386.6) and PEnk (219-229; m/z 1466.6) (Table I). Although MS/MS based sequence identification of rodent aNeo, SP and enkephalin peptides have been reported in previous studies $(44,45)$, the here presented data show the identification of several endogenous dynorphins that has not been described before (Fig. 2, Table I).

Prodynorphin-derived Peptides, but not Substance P, Correlate with LID Severity - The most prominent changes were found in the dorsolateral part of the DA-denervated striatum. Both DynB and aNeo peak intensities were elevated by $50-$ $60 \%$ in high dyskinetic animals compared with low dyskinetic animals and lesion controls $(p<0.05, F(2,15)=12.8$ DynB, $\mathrm{F}=5.7 \mathrm{aNeo}$ ) (Fig. 3, Fig. 4A). For substance $\mathrm{P}$, a small but significant increase of $11 \%$ in the lesioned dorsolateral striatum was observed (Fig. 4A). An up-regulation of prodynorphin
mRNA levels in the dorsolateral striatum have been strongly associated with the severity of axial, limb, and orolingual dyskinesia (21). Simple regression analysis revealed that the peak intensities of both DynB and aNeo, but not substance $\mathrm{P}$, were positively correlated with the sum of axial, limb, and orolingual dyskinesia (DynB: $p<0.001$, Pearson's correlation coefficient $r=0.82$; aNeo: $p<0.01, r=0.68$; SP $p=0.06, r=$ 0.51) (Fig. 4B).

No significant change was observed for these peptides in the dorsomedial striatum. However, similar to prodynorphin mRNA (21), a slight elevation of dynorphin peptides (DynB and aNeo) was noted in the dorsomedial striatum in the two low dyskinetic animals that exhibited locomotive/rotational dyskinesia (Fig. $3 A$, arrowheads).

For the whole dorsal striatum a weaker but still significant increase of aNeo was observed in the high dyskinetic group compared with the low dyskinetic group $(p<0.05$, LD group $0.96 \pm 0.007, \mathrm{HD}$ group $1.48 \pm 0.24$ ), however this difference depended mainly on the elevation in DL striata of HD animals. Similarly, a small elevation of SP, but not DynB, was also detected in the whole dorsal striatum $(p<0.05$, LD group $0.93 \pm 0.029$, HD group $1.09 \pm 0.027$ ).

Dynorphin B Immunoreactivity Surrounds FosB-positive Nuclei-Given the previously described co-expression of striatal PDyn mRNA and FosB-related proteins and their strong association with dyskinesia severity (Andersson et al., 1999), we asked if fully processed dynorphin peptides could be detected in the soma of striatal neurons. First we verified that the number of FosB/deltaFosB immunoreactive nuclei in the dorsolateral striatum was increased in high dyskinetic animals $(F(1,14)=4.7, p<0.05)$ and correlated linearly with axial, limb, and orolingual dyskinesia $(p<0.01, r=0.64)$. Second, double antigen immunohistochemistry using antibodies against dynorphin B peptides and FosB-related proteins was carried out on sections from two high-dyskinetic animals and 
A

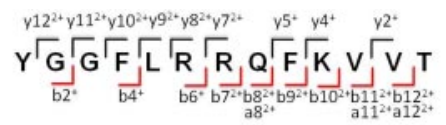

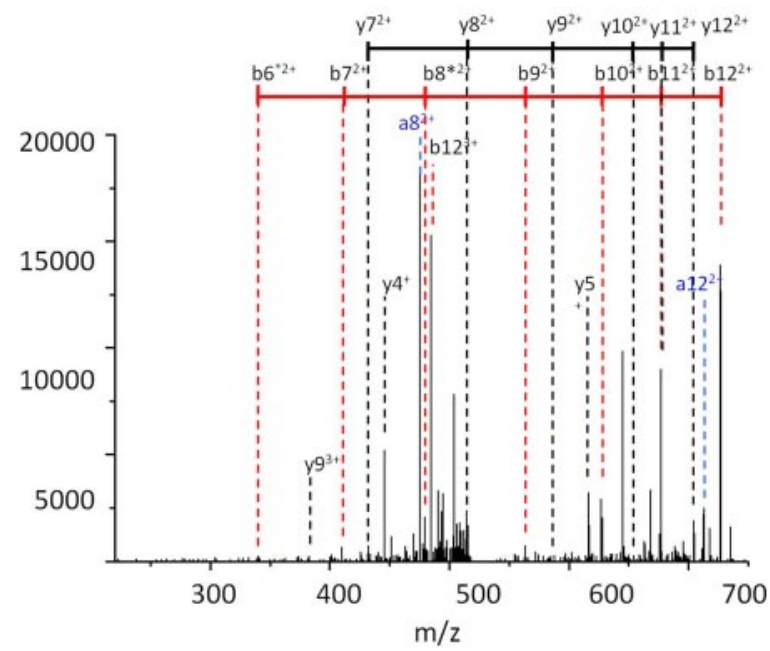

B

$$
\text { Y }
$$

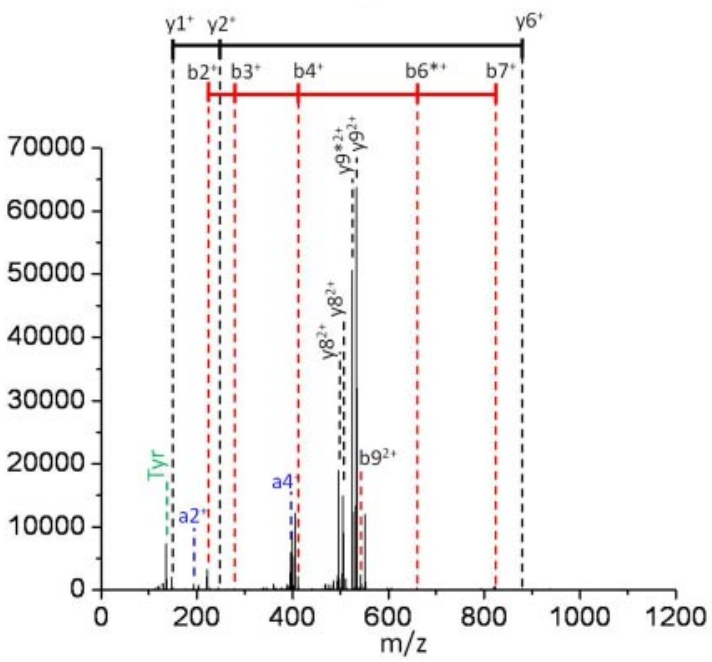

FIG. 2. MS/MS sequence validation of detected dynorphin peptides. Peptide fragmentation spectra of dynorphin $\mathrm{B}(A)$ and $\alpha$-neoendorphin $(B)$ obtained by peptidomic analysis based on SCX/RPLC-ESI FTICR MS and MS/MS. The sequence coverage is indicated and the corresponding sequence tags and fragment ions respectively, are outlined in the spectra.

one low dyskinetic animal. No FosB-immunolabeled nuclei were detected in the DA-denervated striatum of the lowdyskinetic animal, whereas the two high-dyskinetic animals showed distinctly higher striatal levels of both FosB-related proteins and dynorphin B immunoreactivity. To assess how many FosB-immunopositive cells also expressed DynB we counted 200 FosB-positive cells in each dorsolateral striatum of the high dyskinetic animals. Double-positive cells were defined as a FosB-immunoreactive nucleus (red) with dynorphin staining (green) distributed closely around it (Fig. 5).
A

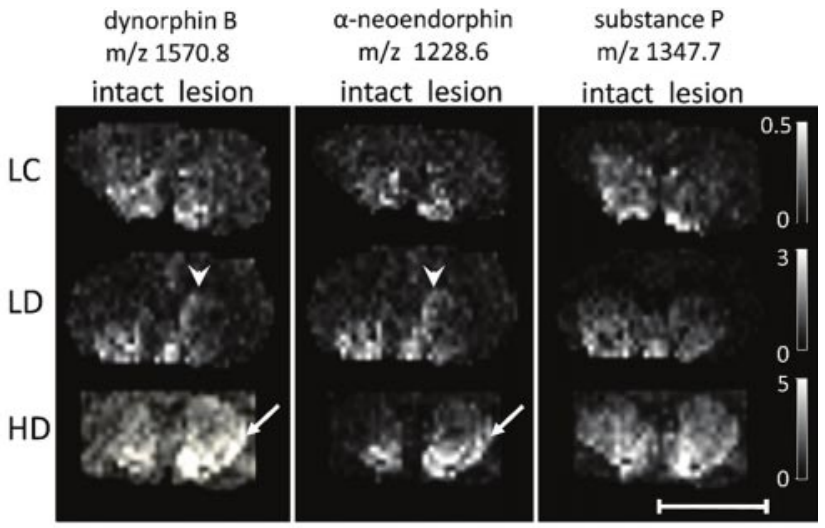

B

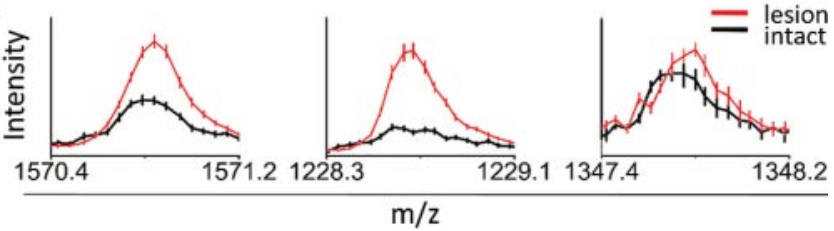

FIG. 3. Alterations of neuropeptides in LID revealed by MALDI IMS. $A$, Spatial ion distribution maps of peptide masses corresponding to dynorphin B (DynB), $\alpha$-neoendorphin (aNeo), and substance $\mathrm{P}$ (SP) in striatal sections of lesion controls (LC), low dyskinetic (LD), and high dyskinetic (HD) animals. Higher levels of DynB, aNeo, and SP peak intensities were observed in the dorsolateral striatum of the lesion compared with the intact side in high dyskinetic animals (arrows). A slight up-regulation of DynB and aNeo intensity can be observed in dorsomedial striatum of an LD animal mainly displaying locomotive/rotational dyskinesia (arrowheads). B, Representative MS traces of dorsolateral striatal peaks corresponding to DynB, aNeo, and SP in the intact (black) and lesion side (red) of high dyskinetic animals (MS data points displayed as mean \pm S.E.). Scale bar $=5$ $\mathrm{mm}$.

Indeed, all FosB-positive cells were double-positive for DynB immunoreactivity in the DA-denervated striatum of high-dyskinetic animals (200/200 cells in both HD animals) (Fig. 5).

Des-tyrosine $\alpha$-Neoendorphin Metabolite Levels Correlate With Dyskinesia Severity-A peptide with $\mathrm{m} / \mathrm{z}$ value of 1065.6 was significantly elevated by $58 \%$ in the DA-depleted dorsolateral striatum in high dyskinetic rats (Fig. $6 A$ and $6 B$ ). The spatial intensity distribution was consistent with that of dynorphin B and $\alpha$-neoendorphin, as demonstrated by multiplexing $\mathrm{m} / \mathrm{z} 1065.6$ (visualized in green) with $\alpha$-neoendorphin (red) (Fig. 6A). Furthermore, simple regression analysis showed a strong correlation between $\mathrm{m} / \mathrm{z} 1065.6$ peak intensity values and dyskinesia scores ( $p<0.01 ; r=0.7$ ) (Fig. 6C). The $\mathrm{m} / \mathrm{z}$ 1065.6 corresponds to the removal of $\mathrm{N}$-terminal tyrosine from $\alpha$-neoendorphin, which was sequence validated by LCMS/MS analysis of striatal peptide extracts (Fig. 6D). No other peptide with a mass of 1065.6 could be detected in the full scan mass spectra.

This prompted a search for other possible des-tyrosine dynorphins. The distribution of des-tyrosine dynorphin $A$ (DynA 2-8, m/z 818.5) and dynorphin B (DynB 2-13, 1407.6) closely matched that of the corresponding intact dynorphin 
FIG. 4. Higher striatal neuropeptide levels in high dyskinetic animals. $A$, Dynorphin B, $\alpha$-neoendorphin and substance $P$ are significantly increased in the DA denervated side in the striatum of high dyskinetic animals (HD) compared with the low dyskinetic (LD) and lesion control group (LC). B, Relative, peptide peak intensities (lesion and intact side) for DynB and aNeo, but not $\mathrm{SP}$, are positively correlated with LID severity expressed as cumulative dyskinesia score. $\left.{ }^{*} p<0.05\right)$.
A

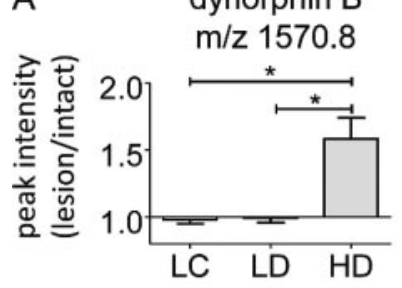

a-neoendorphin $\mathrm{m} / \mathrm{z} 1228.6$

substance $\mathrm{P}$ $\mathrm{m} / \mathrm{z} 1347.7$

B
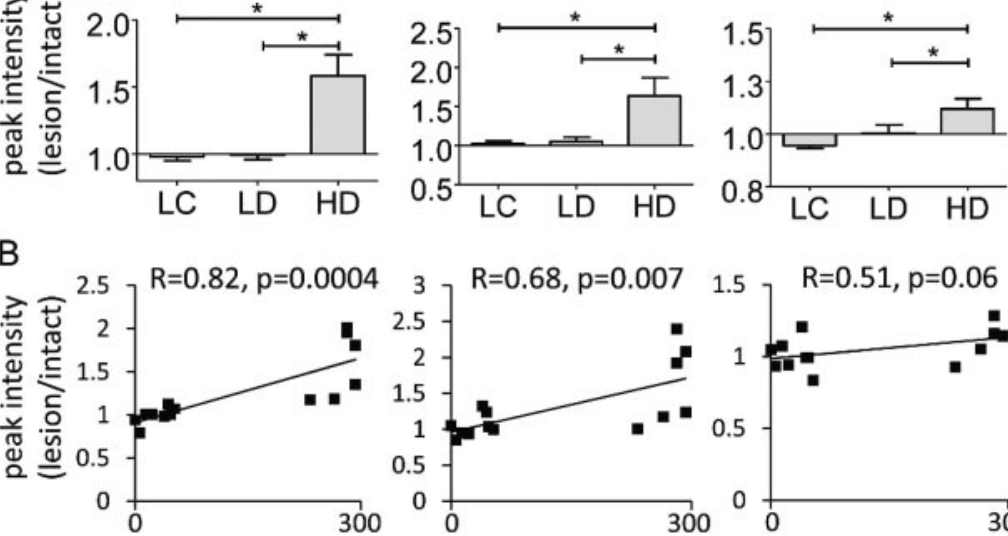

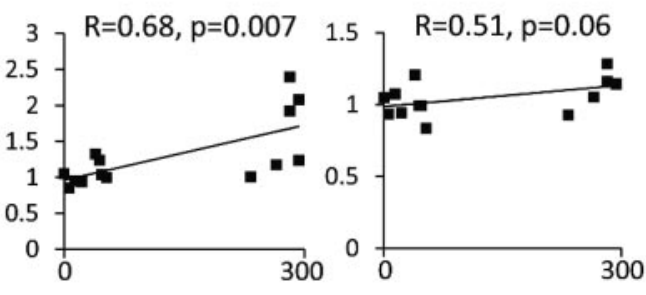

cum. dyskinesia score

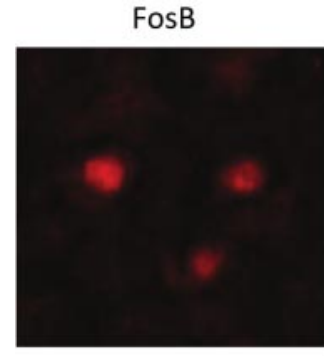

DAPI

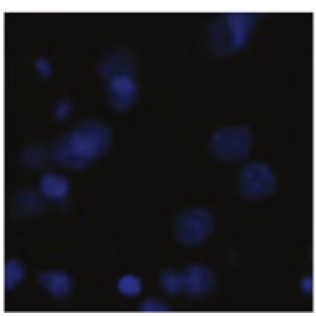

FosB + DynB+DAPI

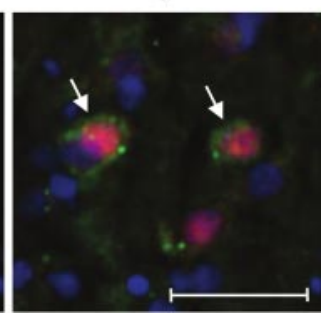

FIG. 5. Double-immunohistochemistry reveal FosB-related proteins and dynorphin B in striatal neurons. FosB immunoreactive neurons (red) were also DynB positive (green). A general nuclear staining, DAPI, was used to visualized all neuronal nuclei (b/ue). FosB was predominantly located in the nucleus and DynB mainly in the soma closely surrounding the nucleus (arrows). Scale bar $=100 \mu \mathrm{m}$.

peptide both in the nucleus accumbens and in the dorsolateral striatum of a few HD animals (Fig. 7A). Furthermore, DynA (2-8) but not des-tyrosine DynB (2-13) could be identified by LC-MS/MS (Table I). However, simple regression analysis showed no correlation between peak intensity and LID severity for both peptide masses. The putative des-tyrosine peptide product of DynA (1-8) was found with higher peak intensity than the intact dynorphin peptide, indicating that bioconversion of DynA (1-8) had occurred to a high degree already 60 min after L-DOPA administration (Fig. 7A).

Detection of Other Dynorphin Related Peptides-Several dynorphin peptides could not be detected by MALDI IMS analysis, including $[\mathrm{M}+\mathrm{H}]^{+}: \mathrm{m} / \mathrm{z} 2147.2$ corresponding to
DynA (1-17), and $m / z 1602.9$ (DynA 1-13). The C-terminal fragment of dynorphin A with $\mathrm{m} / \mathrm{z} 1028$ (DynA 10-17) was detected in a few HD animals and exhibited a similar spatial distribution pattern as DynB and aNeo. However, no consistent increase in HD animals was observed and simple regression analysis showed no correlation between peak intensity and dyskinesia severity. Interestingly, Leu-Enkephalin (YGGFL, $m / z$ 556, LeuEnk or DynA 1-6), which was previously reported to be the main degradation product of striatal dynorphin B could not be detected (46).

Detection of Enkephalins-Most of the detected enkephalins showed no consistent change in abundance when comparing the HD to LD group. A $10 \%$ higher intensity of one enkephalin peptide, PEnk (220-229; m/z 1367.5) was detected in the dorsolateral but not medial striatum of $\mathrm{HD}$ animals $(p<0.05)$ (Fig. 7B). PEnk(220-229) does not include the amino acid sequence $Y G G F M / L$ necessary for binding and activation of opioid receptors, and the distribution did not match that of the L-DOPA-induced increase of dynorphins. By contrast, PEnk (220-229) was found to be predominantly distributed centrally of the striatum (Fig. 7B). A central cosecretion of the peptide together with other PEnk species in the intact striatum was reported in a previous peptidomic study using in vivo microdialysis followed by LC-MSMS (47). In addition, high levels of PEnk (220-229) peptide were observed in the target structure of the striatopallidal projection neurons, the globus pallidus of intact animals (Fig. $1 A$, visualized in purple). No consistent change was observed for Met-Enk-Arg-Phe, Met-Enk-Arg-Gly-Leu, PEnk (198-209), and PEnk (219-229) but a strikingly similar striatal distribution to PEnk (220-229) was observed in a few high dyskinetic animals (Fig. $7 C$ ), suggesting elevated pallidal levels of enkephalins in dyskinetic animals.

Striatal Dynorphin Peptide Validation by IMS of Pdyn KO Mice-For further validation of dynorphin peptide identities, we performed MALDI imaging on striatal sections from wild- 


\section{Dynorphin Peptide Alterations in L-DOPA-induced Dyskinesia}

A

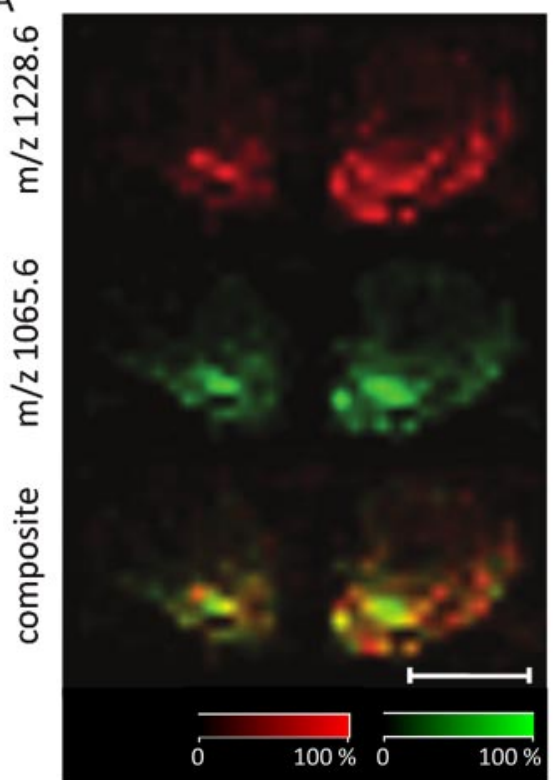

B

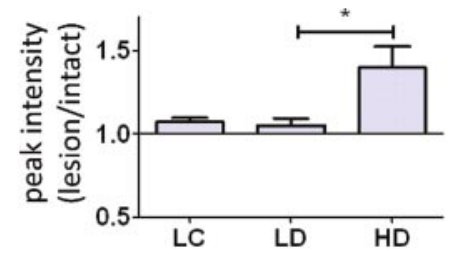

C

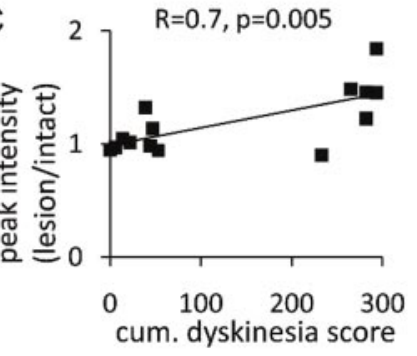

D

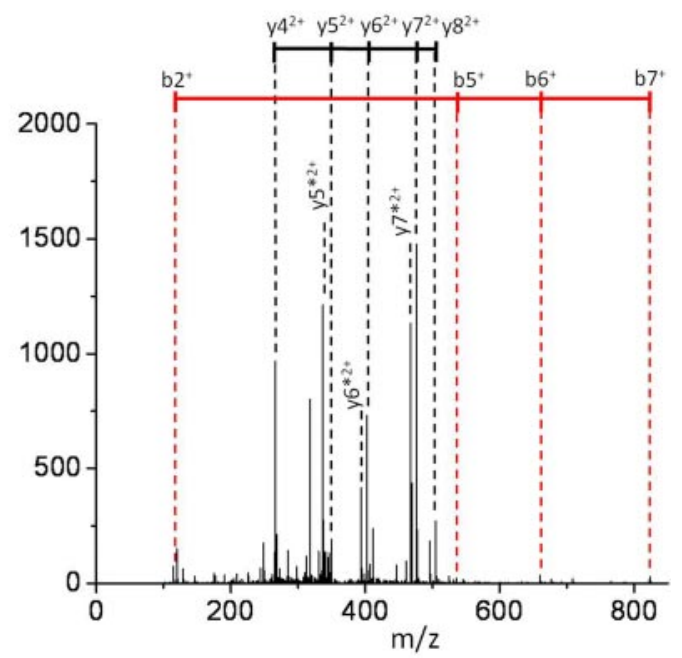

FIG. 6. Des-Tyrosine metabolites of alpha-neoendorphin. A, MALDI IMS ion images revealed that the distribution of aNeo (red; $m / z$ 1228.68) closely matched the localization of a peptide with mass of 1065.6 (green), indicating a putative des-tyrosine form of aNeo. Yellow in composite reveal a substantial overlap between the aNeo and putative des-tyrosine aNeo. Scale bar $=2.5 \mathrm{~mm}$. $B$, Statistical analysis revealed a significant increase of $\mathrm{m} / \mathrm{z} 1065.6$ peak intensity in the dorsolateral striatum of high dyskinetic animals $(p<0.05)$. $C$, Simple regression analysis showed that $\mathrm{m} / \mathrm{z} 1065.6$ correlates positively with dyskinesia severity $(p<0.01)$. $D$, Peptide fragmentation spectra of des-tyrosine aNeo obtained by LC-MS/MS analysis of brain tissue extracts.

type control and Pdyn knockout mice (Fig. 8) (32). Characteristic localization of opioid peptides (aNeo, DynB and desTyraNeo) to the nucleus accumbens were observed in striatal sections of normal control mice similar to the results obtained for the intact striata of rat brain samples (Fig. 3). No dynorphin peptide peaks could be detected in the striatum of Pdyn knockout mice, whereas most peptides ion distribution patterns and abundances were no different from wild type control striatum, for example substance P and PEnk 220-229 (Fig. 8).

\section{DISCUSSION}

A core component of the patophysiology of LID is an increased activity of the direct striatal output pathway according to the traditional view of basal ganglia function $(48,49)$. These striatal medium-sized projection neurons connect with basal ganglia output regions using GABA as neurotransmitter and co-expressing prodynorphin and substance $P$ mRNA. Indeed, increased level of striatal prodynorphin gene expression is one of the most consistent molecular changes associated with the development of LID in different animal models of $\mathrm{PD}(4,5,8,50)$. In addition, antisense mediated knockdown of FosB-related proteins and a concomitant reduction in PDyn mRNA levels indicated a causal role of dynorphins in the development of LID over time (21). However, it has also been suggested that the L-DOPA-induced up-regulation of PDyn mRNA in the dopamine-depleted parkinsonian brain constitutes a homeostatic response of the dynorphin system in order to dampen behavioral exaggerations $(51,52)$. But it has been difficult to interpret the role of dynorphins in LID because the exact nature of prodynorphin processing products has not previously been determined.

The presented results are comprised of MS-based identification and investigation of LID-associated dynorphin processing products with high molecular specificity, which has not been reported before. The introduction of mass spectrometry to the field of comprehensive protein analysis, termed proteomics, has advanced the field significantly because MS offers high specificity while being relative time and cost effective. The only two proteomic studies published so far on LID and PD employed two dimensional-differential gel electrophoresis (2D-DIGE), but because of limitation concerning analysis of low molecular weight compounds $(<5 \mathrm{kDa})$, gel electrophoresis based proteomic studies do not permit the analysis of endogenous neuropeptides, such as the fully processed opioid peptides $(53,54)$. Furthermore, neuropeptide levels are often present in low amounts in the femtomolar range beyond the limits of detection of gel-based proteomics (55). Similarly, few mass spectrometry-based studies have assessed endogenous dynorphin peptides in the normal intact striatum (56-58) and previous studies on dynorphin metabolism were carried out on synthetic peptides that were infused into the intact or parkinsonian striatum or studied in vitro $(46,59,60)$.

A typical obstacle in tissue proteomics and peptidomic studies is the loss of any spatial information beyond the size of the predetermined brain structure. This is highlighted in 
FIG. 7. Additional alterations of striatal opioid peptides in LID. $A$, Destyrosine isoforms of DynB and DynA $(1-8)$ (visualized in green) were found to exhibit a similar spatial distribution as the corresponding intact dynorphin peptide (visualized in red; yellow signify overlap in composite), although no statistical difference could be detected between the different animal groups. Scale bar $=5 \mathrm{~mm}$. $B$, Striatal levels of the enkephalin peptide PEnk (220-229) were significantly increased in high dyskinetic animals $(p<0.05)$. A characteristic distribution centrally in striatum was observed in 4 out of 6 high-dyskinetic animals. The corpus callosum and anterior commissure was visualized by $\mathrm{m} / \mathrm{z}$ 2028 (MBP fragment) in blue. C, Spatial distribution of other enkephalin peptides in one high dyskinetic animal. Although no statistical difference was observed in between the groups the peptides showed a characteristic localization similar to PEnk (220-229).

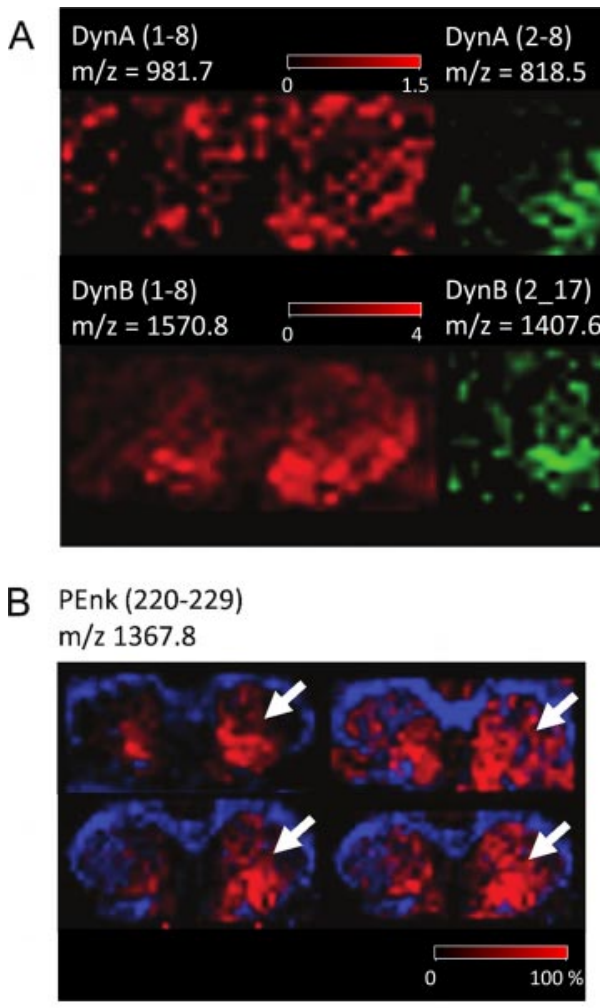

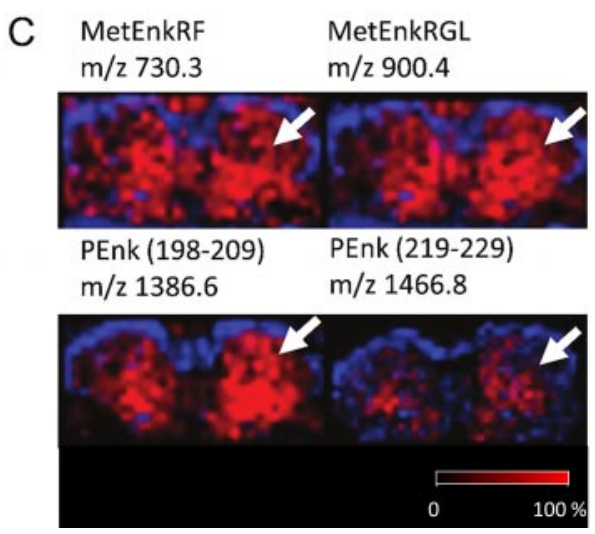

a recent study using neuropeptidomic analysis to detect L-DOPA-induced changes in neuropeptide levels a mouse model of PD (44). Here, no dyskinesia was rated and the neuropeptides were extracted from the entire striatum. Only one PDyn derived peptide, PDyn (177-199) was found significantly elevated, possibly reflecting the fact that highly localized increases in peptide levels can be diluted beyond the level of detection if whole structures are analyzed. By contrast, the main feature of MALDI imaging MS is the preservation of spatial information at sub-millimeter level that allows post analysis assignment without a priori knowledge of the most relevant region of interest (61). However, it is equally possible to assign regions of interest before analysis using the so-called histology-directed strategy combining high-resolution histology to determine clusters of cells with high specificity (62). A main obstacle in IMS is sequence validation of the respective protein and peptide mass peaks. On-tissue MS/MS sequencing of neuropeptides can be done but requires relatively high levels of neuropeptides $(24,25,28,63)$. A more traditional approach for peptide identity validation is to extract peptides from sections or tissue pieces, followed by profound bottom up analysis using standard proteomic and peptidomic techniques as carried out in the current study. Here, one has to keep in mind that IMS allows only for peptide assignment because of the intact mass, whereas the MS/MS experiments that are performed using peptide extracts only serve as an indirect proof of peptide peak assignment. An initial step of verifying the LC-MS/MS based peptide assignments is to check the LC-MS mass chromatogram for other peptides that have a similar mass. In the present study we evaluated all peptide fractions and did indeed not observe other peptides with masses matching dynorphins within a \pm 20 ppm window (cf. mass accuracy in Table I). A further validation strategy performed in this study include immunohistochemistry, which is however highly dependent on the antibody specificity with respect to neuropeptide analysis (64). An ultimate approach for gaining absolute confidence in the neuropeptide identity is comparative MALDI imaging analysis on knockout animals and controls. Indeed, neuropeptide IMS was performed on striatal sections from wild type and Pdyn knockout mice confirmed the Pdyn-derived peptide identities of DynB, aNeo, and des-Tyr aNeo. By contrast, other neuropeptide species such as enkephalins and substance $P$ remained unchanged.

In the present study, chronic intermittent L-DOPA induced higher levels of dynorphin B, $\alpha$-neoendorphin, and substance $P$ neuropeptides in the dorsolateral striatum of animals that displayed predominantly severe axial, limb, and orolingual dyskinesia. In the dorsolateral striatum, the peak intensities of both DynB and aNeo, but not SP, positively correlated with LID severity. This is in accordance with previous studies on Prodynorphin mRNA distribution $(5,21)$. In addition, dynor- 

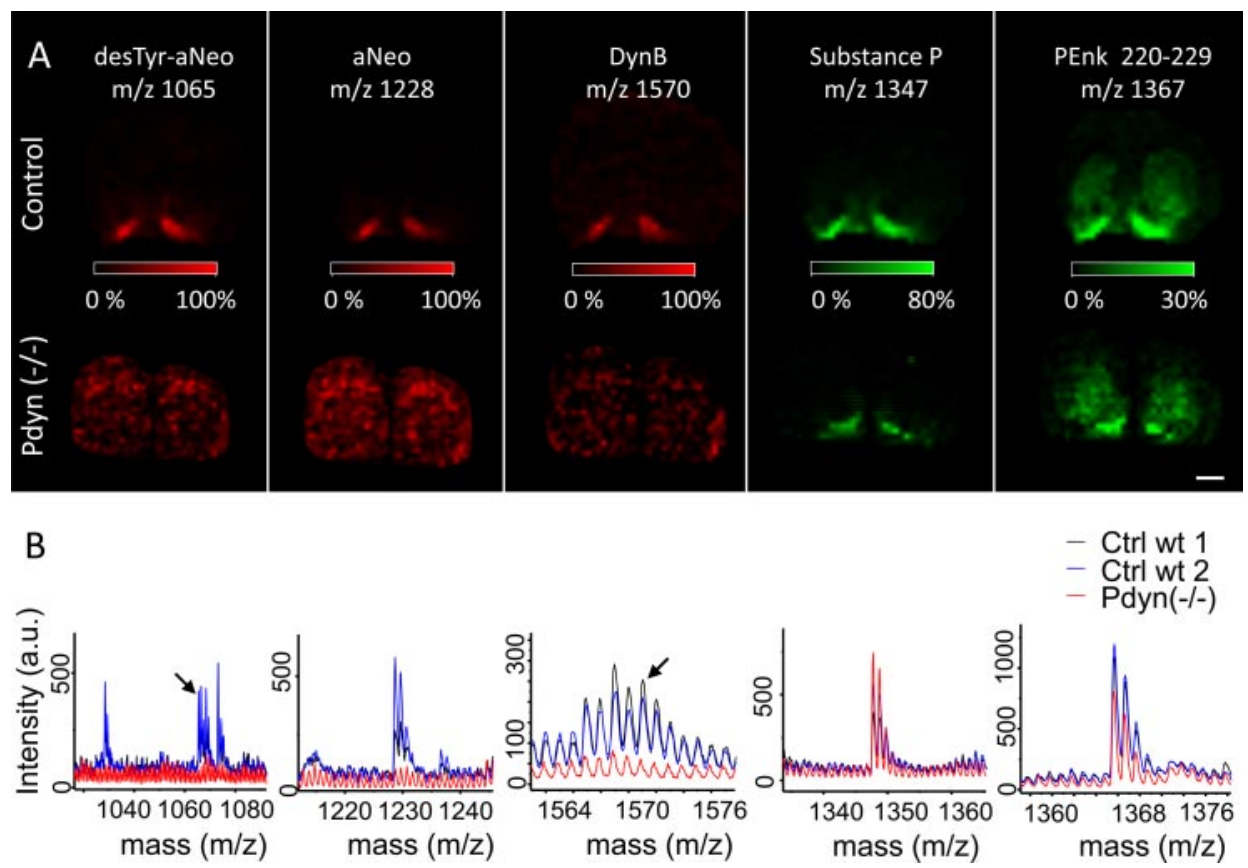

FIG. 8. MALDI IMS of striatal sections reveal loss of dynorphins in Pdyn ${ }^{-1-}$ knockout mice. $A$, Des-tyrosine aNeo, intact aNeo, and Dyn $B$ (visualized in red) are mainly localized to the nucleus accumbens and ventral pallidum of wild type (wt) normal control mice (top panel), whereas only background noise can be detected in the $\mathrm{Pdyn}^{-1-}$ knockout mouse striatum (corresponding bottom panel). In order to reveal the distribution of spectral noise in the $\mathrm{Pdyn}^{-1-}$ knockout, the intensity scalebars were set to $100 \%$ of the intensity of the brightest pixel in each individual MALDI IMS image. Other neuropeptides, such as substance P and PEnk (220-229), were not affected by deletion of the Pdyn gene

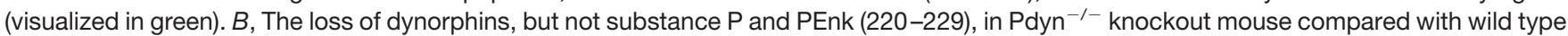
controls is evident by the average mass spectra from nucleus accumbens. Scale bar $=1 \mathrm{~mm}$.

phin B-immunoreactive striatal cells have been observed in a mouse model of LID (65). Other studies have shown that relatively high doses of L-DOPA (100 $\mathrm{mg} / \mathrm{kg}$ per day) or repeated apomorphine treatment induced high levels of striatal $\operatorname{DynA}(1-8)$ and DynA(1-17) immunoreactivity, however DynB and aNeo were not assessed in these studies $(66,67)$. We did not observe any L-DOPA-induced regulation of dynorphin A-related peptides, and probably this is partly because of the relative low dose L-DOPA used in the present study $(8 \mathrm{mg} / \mathrm{kg}$ per AQ: C day) and partly because of the moderate number of animals.

Sometimes mRNA based measurements do not reflect the levels of proteins or peptides. For example, PDyn mRNA levels are reduced by $40-50 \%$ in the DA-denervated striatum of the rat model of $\operatorname{PD}(5,21)$, whereas the dynorphin peptide levels remain unchanged compared with the intact striatum (lesion controls in Fig. 4 (14-16)). The reduction of PDyn mRNA synthesis is probably not surprising, as this reflects the reduced activity of PDyn-expressing medial spiny neurons in the parkinsonian brain. Reduced activity means less release of dynorphin peptides, therefore there is no requirement to replenish dynorphins and Pdyn transcription can be reduced.

Traditionally propeptide processing into the mature neuropeptide is thought to occur during the axonal transportation of the propeptide to its target release area. A recent study indicates that a significant amount of processing occurs in axonal terminals and dendrites, as the intact $14-\mathrm{kDa}$ prodynorphin propeptide has been detected in dense core vesicles in hippocampal mossy fibers (38). In order to assess the cellular distribution of L-DOPA-induced DynB, double antigen immunohistochemistry was performed. L-DOPA-induced FosB-immunopositive neuronal nuclei were surrounded by high levels of DynB immunoreactivity and the close proximity of fully mature DynB to the nuclei indicated that substantial dynorphin propeptide processing occurs relatively early after translation. Interestingly, MALDI IMS could not detect any precursor species such as big dynorphin (Big DynAB 1-32, m/z 3982.25) and leumorphin (dynorphin B 1-29; $\mathrm{m} / \mathrm{z} 3317.6$ ). However the regional location of the striatal full-length propeptide (14-15 $\mathrm{kDa}$ ) remains elusive as another MALDI IMS protocol would have to be applied for its detection (24). The presence of L-DOPA-induced elevation of fully processed aNeo and DynB in striatum indicates that these dynorphins may be released locally upon dopaminergic stimulation.

The endogenous dynorphins mainly display high affinity to the kappa opioid receptor (KOP), but can also interact with the other classical opioid receptors mu (MOP) and delta (DOP) with somewhat lower binding affinities $(68,69)$. In particular the shorter dynorphins, such as aNeo, display the least selectivity being active in the nanomolar range at both DOPr and MOPr (68). The present study shows that prodynorphin processing in the striatonigral projection neurons mainly results in DynB and aNeo that may result in abnormal signaling through 
the delta and mu opioid receptor instead of KOP receptors. Indeed, both DOPr and MOPr-antagonists attenuate LID in the MPTP-lesioned marmoset (4). Along the same line of reasoning it may not be surprising that several studies have reported anti-dyskinetic effects of kappa-agonist administration in rat and monkey models of PD, however in some studies the anti-parkinsonian effect of L-DOPA was also diminished and side-effects reduced the therapeutic value (70-72). This also highlights the problem of opioid agonist or antagonist therapy that inevitably affects receptors outside the intended target area and calls for a search of molecular changes uniquely associated with dyskinesia.

Opioid receptor binding assays provide some insight into striatal and striatonigral opioid transmission associated with dyskinesia. In the rat model of LID in PD, the DA-denervation induced a decrease in striatal MOP and DOP receptor binding, but only striatal KOP receptor binding was negatively correlated with LID (73). By contrast, there was no correlation with striatal KOPr, DOPr, or MOPr, binding and LID in the MPTP-model of macaque monkey (8). In both these studies significant negative correlations between dyskinesia and KOP and MOP receptor-binding in basal ganglia output structures indicated increased striatonigral opioid transmission in dyskinesia, whereas opioid receptor binding in the striatum was less associated with LID severity. Taken together, this indicates that DynB and aNeo mainly act in SN through opioid receptor binding but that the role of opioid transmission in the striatum remains unclear.

In the study presented here the animals were sacrificed at the time when the rats exhibit most dyskinesia, $1 \mathrm{~h}$ after the last L-DOPA injection, in order to detect dynorphin metabolites by MALDI IMS. No evidence was found of striatal bioconversion of aNeo and DynB into enkephalins, including Leu-Enk or Leu-Enk-Arg. Opioid peptides are mainly inactivated by peptidases and proteases, and can thereby be converted to other bioactive peptide products (74). For example, the removal of the $\mathrm{N}$-terminal tyrosine effectively reduces opioid receptor binding and activation (75). MALDI IMS revealed that the levels of a novel des-tyrosine dynorphin, destyrosine aNeo, correlated well with LID severity and exhibited a spatial distribution pattern identical to aNeo, the intact precursor peptide. Indeed several groups have noted that many synthetic dynorphins are rapidly converted into their destyrosine form both in vivo and in vitro (46, 76-78). In particular, the rapid bioconversion of DynB and aNeo into their destyrosine form is almost $100 \%$ complete in the absence of aminopeptidase inhibitors, indicating that removal of the initial tyrosine constitutes a physiological mechanism of inactivation of opioid peptide activity in the striatum $(46,77)$. MALDI IMS of substantia nigra sections from the same rats included in this study displayed no L-DOPA-induced up-regulation of des-tyrosine aNeo or other des-tyrosine dynorphins, despite a strong association of aNeo and DynB with LID severity (unpublished data). This suggests that the increase in des-ty- rosine aNeo is not simply because of unspecific degradation of striatal neuropeptides and indicate a biologically relevant dissociation in dynorphin bioconversion in striatum compared with the substantia nigra, which is in accordance with previously published results from normal intact rat brain (46). No other dynorphin-derived $\mathrm{C}$ - or N-terminal fragments could be detected in the striatum by MALDI IMS analysis, further substantiating that des-tyrosine dynorphins are not produced by unspecific enzymatic degradation. MALDI MS analysis of synthetic dynorphin peptides (20 nmol on target) did not reveal in source fragmentation resulting in loss of the N-terminal tyrosine. Furthermore, if the des-tyrosine aNeo is a product of in source decay the correlation coefficient of individual pixel peak intensities between aNeo and des-tyrosine aNeo would be close to 1. Similarly the correlation coefficient between the first and second isotope of dynorphins would be close to 1, and indeed the Pearson $\mathrm{R}$ ranged from 0.93 to 0.97 for the first and second isotope of des-tyrosine aNeo, aNeo, and dynB. A higher correlation coefficient was found between aNeo and des-tyrosine aNeo (0.83) than between des-tyrosine aNeo and dynorphin B (0.62) or the unrelated proenkephalin 220-229 (0.17) that was used as a negative control. The close, but not perfect linear relationship between des-tyrosine aNeo and aNeo may also indicate that the removal of tyrosine occurs after synaptic release rather than as part of the process of neuropeptide maturation. One other potential mechanism of striatal des-tyrosine dynorphins functionality might be the based on nonopioid receptor-dependant interactions with striatal NMDA receptors (79-82). As such, the des-tyrosine dynorphins may constitute a functional compensatory mechanism for countervailing L-DOPA-induced overstimulation of striatal DA D1 receptors. One of the objectives in the field of LID research must be to dissociate between L-DOPAinduced anti-parkinsonian and dyskinesiogenic effects and to find novel molecular targets, such as the des-tyrosine dynorphins, in order to tailor new pharmaceutical interventions to block the development or maintenance of LID.

Acknowledgments-We thank Prof. Ingrid Nylander, Sara Palm, Katarina Josefsson, and Prof. Georgy Bakalkin for assistance with preparing brain peptides for LC-MS/MS and for the kind gift of the dynorphin B antibody. The Pdyn knockout mice were provided by Dr. Ute Hochgeschwender and the brains a gift from Dr. Tatjana Yakovleva and Prof. Georgy Bakalkin. We thank Helena Cordeiro for excellent technical assistance.

\footnotetext{
* This work was funded by the Swedish Research Council grant \#522-2006-6414 (MA), 521-2007-5407 (MA), 342-2004-3944 (JB), and 621-2008-3562 (JB), the Swedish Parkinson Foundation (MA), the Swedish Royal Academy of Sciences (MA, JH), and Åke Wibergs Foundation (JH, MA).

S This article contains supplemental Fig. S1.

\| To whom correspondence should be addressed: Department of Pharmaceutical Biosciences, Drug Safety and Toxicology, Uppsala University, Box 594, SE-751 24 Uppsala, Sweden. Tel.: +46 18 4717207; E-mail: malin.andersson@farmbio.uu.se.

** Both authors contributed equally to this work.
} 


\section{REFERENCES}

1. Nadjar, A., Gerfen, C. R., and Bezard, E. (2009) Priming for I-dopa-induced dyskinesia in Parkinson's disease: a feature inherent to the treatment or the disease? Prog. Neurobiol. 87, 1-9

2. Nisbet, A. P., Foster, O. J., Kingsbury, A., Eve, D. J., Daniel, S. E., Marsden, C. D., and Lees, A. J. (1995) Preproenkephalin and preprotachykinin messenger RNA expression in normal human basal ganglia and in Parkinson's disease. Neuroscience 66, 361-376

3. Calon, F., Birdi, S., Rajput, A. H., Hornykiewicz, O., Bédard, P. J., and Di Paolo, T. (2002) Increase of preproenkephalin mRNA levels in the putamen of Parkinson disease patients with levodopa-induced dyskinesias. J. Neuropathol. Exp. Neurol. 61, 186-196

4. Henry, B., Duty, S., Fox, S. H., Crossman, A. R., and Brotchie, J. M. (2003) Increased striatal pre-proenkephalin B expression is associated with dyskinesia in Parkinson's disease. Exp. Neurol. 183, 458-468

5. Cenci, M. A., Lee, C. S., and Björklund, A. (1998) L-DOPA-induced dyskinesia in the rat is associated with striatal overexpression of prodynorphin- and glutamic acid decarboxylase mRNA. Eur. J. Neurosci. 10, 2694-2706

6. Lundblad, M., Picconi, B., Lindgren, H., and Cenci, M. A. (2004) A model of L-DOPA-induced dyskinesia in 6-hydroxydopamine lesioned mice: relation to motor and cellular parameters of nigrostriatal function. Neurobiol. Dis. 16, 110-123

7. Winkler, C., Kirik, D., Björklund, A., and Cenci, M. A. (2002) L-DOPAinduced dyskinesia in the intrastriatal 6-hydroxydopamine model of parkinson's disease: relation to motor and cellular parameters of nigrostriatal function. Neurobiol. Dis. 10, 165-186

8. Aubert, I., Guigoni, C., Li, Q., Dovero, S., Bioulac, B. H., Gross, C. E., Crossman, A. R., Bloch, B., and Bezard, E. (2007) Enhanced preproenkephalin-B-derived opioid transmission in striatum and subthalamic nucleus converges upon globus pallidus internalis in L-3,4-dihydroxyphenylalanine-induced dyskinesia. Biol. Psychiatry. 61, 836-844

9. Tel, B. C., Zeng, B. Y., Cannizzaro, C., Pearce, R. K., Rose, S., and Jenner, P. (2002) Alterations in striatal neuropeptide mRNA produced by repeated administration of L-DOPA, ropinirole or bromocriptine correlate with dyskinesia induction in MPTP-treated common marmosets. Neuroscience 115, 1047-1058

10. Tamim, M. K., Samadi, P., Morissette, M., Grégoire, L., Ouattara, B., Levesque, D., Rouillard, C., and Di Paolo, T. (2010) Effect of non-dopaminergic drug treatment on Levodopa induced dyskinesias in MPTP monkeys: common implication of striatal neuropeptides. Neuropharmacology 58, 286-296

11. Fox, S. H., Chuang, R., and Brotchie, J. M. (2009) Serotonin and Parkinson's disease: On movement, mood, and madness. Mov. Disord. 24, 1255-1266

12. Höllt, V. (1986) Opioid peptide processing and receptor selectivity. Annu. Rev. Pharmacol. Toxicol. 26, 59-77

13. Day, R., Lazure, C., Basak, A., Boudreault, A., Limperis, P., Dong, W., and Lindberg, I. (1998) Prodynorphin processing by proprotein convertase 2. Cleavage at single basic residues and enhanced processing in the presence of carboxypeptidase activity. J. Biol. Chem. 273, 829-836

14. Taquet, H., Javoy-Agid, F., Giraud, P., Legrand, J. C., Agid, Y., and Cesselin, F. (1985) Dynorphin levels in parkinsonian patients: Leu5-enkephalin production from either proenkephalin $A$ or prodynorphin in human brain. Brain Res. 341, 390-392

15. Taquet, H., Javoy-Agid, F., Hamon, M., Legrand, J. C., Agid, Y., and Cesselin, F. (1983) Parkinson's disease affects differently Met5- and Leu5-enkephalin in the human brain. Brain Res. 280, 379-382

16. Sivam, S. P. (1991) Dopamine dependent decrease in enkephalin and substance $P$ levels in basal ganglia regions of postmortem parkinsonian brains. Neuropeptides 18, 201-207

17. Klintenberg, R., Svenningsson, P., Gunne, L., and Andrén, P. E. (2002) Naloxone reduces levodopa-induced dyskinesias and apomorphine-induced rotations in primate models of parkinsonism. J. Neural. Transm. 109, 1295-1307

18. Samadi, P., Grégoire, L., and Bédard, P. J. (2003) Opioid antagonists increase the dyskinetic response to dopaminergic agents in parkinsonian monkeys: interaction between dopamine and opioid systems. Neuropharmacology 45, 954-963

19. Samadi, P., Grégoire, L., and Bédard, P. J. (2004) The opioid agonist morphine decreases the dyskinetic response to dopaminergic agents in parkinsonian monkeys. Neurobiol. Dis. 16, 246-253

20. Rascol, O., Fabre, N., Blin, O., Poulik, J., Sabatini, U., Senard, J. M., Ané, M., Montastruc, J. L., and Rascol, A. (1994) Naltrexone, an opiate antagonist, fails to modify motor symptoms in patients with Parkinson's disease. Mov. Disord. 9, 437-440

21. Andersson, M., Hilbertson, A., and Cenci, M. A. (1999) Striatal fosB expression is causally linked with L-DOPA-induced abnormal involuntary movements and the associated upregulation of striatal prodynorphin mRNA in a rat model of Parkinson's disease. Neurobiol. Dis. 6, 461-474

22. Caprioli, R. M., Farmer, T. B., and Gile, J. (1997) Molecular imaging of biological samples: localization of peptides and proteins using MALDITOF MS. Anal. Chem. 69, 4751-4760

23. Goodwin, R. J., Pennington, S. R., and Pitt, A. R. (2008) Protein and peptides in pictures: imaging with MALDI mass spectrometry. Proteomics 8, 3785-3800

24. Andersson, M., Groseclose, M. R., Deutch, A. Y., and Caprioli, R. M. (2008) Imaging mass spectrometry of proteins and peptides: 3D volume reconstruction. Nat. Methods 5, 101-108

25. Groseclose, M. R., Andersson, M., Hardesty, W. M., and Caprioli, R. M. (2007) Identification of proteins directly from tissue: in situ tryptic digestions coupled with imaging mass spectrometry. J. Mass Spectrom. 42, 254-262

26. Stoeckli, M., Chaurand, P., Hallahan, D. E., and Caprioli, R. M. (2001) Imaging mass spectrometry: a new technology for the analysis of protein expression in mammalian tissues. Nat. Med. 7, 493-496

27. Rubakhin, S. S., Greenough, W. T., and Sweedler, J. V. (2003) Spatial profiling with MALDI MS: Distribution of neuropeptides within single neurons. Anal. Chem. 75, 5374-5380

28. Verhaert, P. D., Pinkse, M. W., Strupat, K., and Conaway, M. C. (2010) Imaging of similar mass neuropeptides in neuronal tissue by enhanced resolution MALDI MS with an ion trap-Orbitrap hybrid instrument. Methods Mol. Biol. 656, 433-449

29. Zimmerman, T. A., Rubakhin, S. S., Romanova, E. V., Tucker, K. R., and Sweedler, J. V. (2009) MALDI mass spectrometric imaging using the stretched sample method to reveal neuropeptide distributions in aplysia nervous tissue. Anal. Chem. 81, 9402-9409

30. Altelaar, A. F., Klinkert, I., Jalink, K., de Lange, R. P., Adan, R. A., Heeren, R. M., and Piersma, S. R. (2006) Gold-enhanced biomolecular surface imaging of cells and tissue by SIMS and MALDI mass spectrometry. Anal. Chem. 78, 734-742

31. Chen, R., Hui, L., Sturm, R. M., and Li, L. (2009) Three dimensional mapping of neuropeptides and lipids in crustacean brain by mass spectral imaging. J. Am. Soc. Mass Spectrom. 20, 1068-1077

32. Sharifi, N., Diehl, N., Yaswen, L., Brennan, M. B., and Hochgeschwender, U. (2001) Generation of dynorphin knockout mice. Brain Res. Mol. Brain Res. 86, 70-75

33. Paxinos, G., and Watson, C. (2007) The rat brain in stereotaxic coordinates, 6 Ed., Elsevier Academic Press, San Diego

34. Schallert, T., and Tillerson, J. (2000) Central Nervous System Diseases: Innovative Models of CNS Diseases from Molecule to Therapy. In: Emerich, D., Dean, R. I., and Sanberg, P., eds. Central Nervous System Diseases:Innovative Models of CNS Diseases from Molecule to Therapy, pp. 131-151, Humana Press, Totowa, NJ

35. Tillerson, J. L., Cohen, A. D., Philhower, J., Miller, G. W., Zigmond, M. J., and Schallert, T. (2001) Forced limb-use effects on the behavioral and neurochemical effects of 6-hydroxydopamine. J. Neurosci. 21, 4427-4435

36. Tusher, V. G., Tibshirani, R., and Chu, G. (2001) Significance analysis of microarrays applied to the ionizing radiation response. Proc. Natl. Acad. Sci. U.S.A. 98, 5116-5121

37. Vincent, S., Hökfelt, T., Christensson, I., and Terenius, L. (1982) Immunohistochemical evidence for a dynorphin immunoreactive striato-nigral pathway. Eur. J. Pharmacol. 85, 251-252

38. Yakovleva, T., Bazov, I., Cebers, G., Marinova, Z., Hara, Y., Ahmed, A., Vlaskovska, M., Johansson, B. R., Hochgeschwender, U., Singh, I. N., Bruce-Keller, A. J., Hurd, Y. L., Kaneko, T., Terenius, L., Ekström, T. J., Hauser, K. F., Pickel, V. M., and Bakalkin, G. (2006) Prodynorphin storage and processing in axon terminals and dendrites. Faseb J. 20, 2124-2126

39. Bergström, L., Christensson, I., Folkesson, R., Stenström, B., and Terenius, L. (1983) An ion exchange chromatography and radioimmunoassay pro- 
cedure for measuring opioid peptides and substance P. Life Sci. 33, 1613-1619

40. Christensson-Nylander, I., Herrera-Marschitz, M., Staines, W., Hokfelt, T., Terenius, L., Ungerstedt, U., Cuello, C., Oertel, W. H., and Goldstein, M. (1986) Striato-nigral dynorphin and substance $P$ pathways in the rat. I. Biochemical and immunohistochemical studies. Exp. Brain Res. 64, 169-192

41. Craig, R., and Beavis, R. C. (2004) TANDEM: matching proteins with tandem mass spectra. Bioinformatics 20, 1466-1467

42. Perkins, D. N., Pappin, D. J., Creasy, D. M., and Cottrell, J. S. (1999) Probability-based protein identification by searching sequence databases using mass spectrometry data. Electrophoresis 20, 3551-3567

43. Chalkley, R. J., Baker, P. R., Huang, L., Hansen, K. C., Allen, N. P., Rexach, M., and Burlingame, A. L. (2005) Comprehensive analysis of a multidimensional liquid chromatography mass spectrometry dataset acquired on a quadrupole selecting, quadrupole collision cell, time-of-flight mass spectrometer: II. New developments in Protein Prospector allow for reliable and comprehensive automatic analysis of large datasets. $\mathrm{Mol}$. Cell. Proteomics 4, 1194-1204

44. Nilsson, A., Fälth, M., Zhang, X., Kultima, K., Sköld, K., Svenningsson, P., and Andrén, P. E. (2009) Striatal alterations of secretogranin-1, somatostatin, prodynorphin, and cholecystokinin peptides in an experimental mouse model of Parkinson disease. Mol. Cell. Proteomics 8, 1094-1104

45. Fricker, L. D. (2010) Analysis of mouse brain peptides using mass spectrometry-based peptidomics: implications for novel functions ranging from non-classical neuropeptides to microproteins. Mol. Biosyst. 6, 1355-1365

46. Sandin, J., Tan-No, K., Kasakov, L., Nylander, I., Winter, A., Silberring, J., and Terenius, L. (1997) Differential metabolism of dynorphins in substantia nigra, striatum, and hippocampus. Peptides 18, 949-956

47. Haskins, W. E., Watson, C. J., Cellar, N. A., Powell, D. H., and Kennedy, R. T. (2004) Discovery and neurochemical screening of peptides in brain extracellular fluid by chemical analysis of in vivo microdialysis samples. Anal. Chem. 76, 5523-5533

48. Bezard, E., Brotchie, J. M., and Gross, C. E. (2001) Pathophysiology of levodopa-induced dyskinesia: potential for new therapies. Nat. Rev. Neurosci. 2, 577-588

49. Cenci, M. A., and Konradi, C. (2010) Maladaptive striatal plasticity in LDOPA-induced dyskinesia. Prog. Brain Res. 183, 209-233

50. Lundblad, M., Vaudano, E., and Cenci, M. A. (2003) Cellular and behavioural effects of the adenosine A2a receptor antagonist $\mathrm{KW}-6002$ in a rat model of I-DOPA-induced dyskinesia. J. Neurochem. 84, 1398-1410

51. Steiner, H., and Gerfen, C. R. (1998) Role of dynorphin and enkephalin in the regulation of striatal output pathways and behavior. Exp. Brain Res. 123, 60-76

52. Steiner, H., and Gerfen, C. R. (1993) Cocaine-induced c-fos messenger RNA is inversely related to dynorphin expression in striatum. J. Neurosci. 13, 5066-5081

53. Valastro, B., Dekundy, A., Krogh, M., Lundblad, M., James, P., Danysz, W., Quack, G., and Cenci, M. A. (2007) Proteomic analysis of striatal proteins in the rat model of L-DOPA-induced dyskinesia. J. Neurochem. 102, 1395-1409

54. Scholz, B., Svensson, M., Alm, H., Sköld, K., Fälth, M., Kultima, K., Guigoni, C., Doudnikoff, E., Li, Q., Crossman, A. R., Bezard, E., and Andrén, P. E. (2008) Striatal proteomic analysis suggests that first L-dopa dose equates to chronic exposure. PLOS ONE 3, e1589

55. Strand, F. L. (2003) Neuropeptides: general characteristics and neuropharmaceutical potential in treating CNS disorders. Prog. Drug Res. 61, 1-37

56. Parkin, M. C., Wei, H., O'Callaghan, J. P., and Kennedy, R. T. (2005) Sample-dependent effects on the neuropeptidome detected in rat brain tissue preparations by capillary liquid chromatography with tandem mass spectrometry. Anal. Chem. 77, 6331-6338

57. Wei, H., Nolkrantz, K., Parkin, M. C., Chisolm, C. N., O'Callaghan, J. P., and Kennedy, R. T. (2006) Identification and quantification of neuropeptides in brain tissue by capillary liquid chromatography coupled off-line to MALDI-TOF and MALDI-TOF/TOF-MS. Anal. Chem. 78, 4342-4351

58. Li, Q., Zubieta, J. K., and Kennedy, R. T. (2009) Practical aspects of in vivo detection of neuropeptides by microdialysis coupled off-line to capillary LC with multistage MS. Anal. Chem. 81, 2242-2250

59. Reed, B., Zhang, Y., Chait, B. T., and Kreek, M. J. (2003) Dynorphin A(1-17) biotransformation in striatum of freely moving rats using microdialysis and matrix-assisted laser desorption/ionization mass spectrometry. J. Neurochem. 86, 815-823

60. Klintenberg, R., and Andrén, P. E. (2005) Altered extracellular striatal in vivo biotransformation of the opioid neuropeptide dynorphin $A(1-17)$ in the unilateral 6-OHDA rat model of Parkinson's disease. J. Mass Spectrom. 40, 261-270

61. Oppenheimer, S. R., Mi, D., Sanders, M. E., and Caprioli, R. M. (2010) Molecular analysis of tumor margins by MALDI mass spectrometry in renal carcinoma. J. Proteome. Res. 9, 2182-2190

62. Cornett, D. S., Mobley, J. A., Dias, E. C., Andersson, M., Arteaga, C. L., Sanders, M. E., and Caprioli, R. M. (2006) A novel histology-directed strategy for MALDI-MS tissue profiling that improves throughput and cellular specificity in human breast cancer. Mol. Cell. Proteomics 5, 1975-1983

63. Li, L., Garden, R. W., Romanova, E. V., and Sweedler, J. V. (1999) In situ sequencing of peptides from biological tissues and single cells using MALDI-PSD/CID analysis. Anal. Chem. 71, 5451-5458

64. Christensson-Nylander, I., Nyberg, F., Ragnarsson, U., and Terenius, L. (1985) A general procedure for analysis of proenkephalin B derived opioid peptides. Regul. Pept. 11, 65-76

65. Darmopil, S., Martin, A. B., De Diego, I. R., Ares, S., and Moratalla, R. (2009) Genetic inactivation of dopamine D1 but not D2 receptors inhibits LDOPA-induced dyskinesia and histone activation. Biol. Psychiatry 66, 603-613

66. Gerfen, C. R., McGinty, J. F., and Young, W. S., 3rd (1991) Dopamine differentially regulates dynorphin, substance $P$, and enkephalin expression in striatal neurons: in situ hybridization histochemical analysis. J. Neurosci. 11, 1016-1031

67. Engber, T. M., Susel, Z., Kuo, S., Gerfen, C. R., and Chase, T. N. (1991) Levodopa replacement therapy alters enzyme activities in striatum and neuropeptide content in striatal output regions of 6-hydroxydopamine lesioned rats. Brain Res. 552, 113-118

68. Merg, F., Filliol, D., Usynin, I., Bazov, I., Bark, N., Hurd, Y. L., Yakovleva, T., Kieffer, B. L., and Bakalkin, G. (2006) Big dynorphin as a putative endogenous ligand for the kappa-opioid receptor. J. Neurochem. 97, 292-301

69. Schwarzer, C. (2009) 30 years of dynorphins-new insights on their functions in neuropsychiatric diseases. Pharmacol. Ther. 123, 353-370

70. Marin, C., Bové, J., Bonastre, M., and Tolosa, E. (2003) Effect of acute and chronic administration of U50,488, a kappa opioid receptor agonist, in 6-OHDA-lesioned rats chronically treated with levodopa. Exp. Neurol. 183, 66-73

71. Cox, H., Togasaki, D. M., Chen, L., Langston, J. W., Di Monte, D. A., and Quik, M. (2007) The selective kappa-opioid receptor agonist U50,488 reduces L-dopa-induced dyskinesias but worsens parkinsonism in MPTP-treated primates. Exp Neurol 205, 101-107

72. Ikeda, K., Yoshikawa, S., Kurokawa, T., Yuzawa, N., Nakao, K., and Mochizuki, H. (2009) TRK-820, a selective kappa opioid receptor agonist, could effectively ameliorate L-DOPA-induced dyskinesia symptoms in a rat model of Parkinson's disease. Eur. J. Pharmacol. 620, 42-48

73. Johansson, P. A., Andersson, M., Andersson, K. E., and Cenci, M. A. (2001) Alterations in cortical and basal ganglia levels of opioid receptor binding in a rat model of L-DOPA-induced dyskinesia. Neurobiol. Dis. 8, 220-239

74. Nyberg, F., and Hallberg, M. (2007) Peptide conversion-a potential pathway modulating G-protein signaling. Curr. Drug Targets 8, 147-154

75. Walker, J. M., Moises, H. C., Coy, D. H., Baldrighi, G., and Akil, H. (1982) Nonopiate effects of dynorphin and des-Tyr-dynorphin. Science 218, 1136-1138

76. Young, E. A., Walker, J. M., Houghten, R., and Akil, H. (1987) The degradation of dynorphin-A in brain-tissue in vivo and in vitro. Peptides. 8, 701-707

77. Nylander, I., Tan-No, K., Winter, A., and Silberring, J. (1995) Processing of prodynorphin-derived peptides in striatal extracts-Identification by electrospray-ionization mass spectrometry linked to size-exclusion chromatography Life Sci. 57, 123-129

78. Prokai, L., and Zharikova, A. D. (1998) Identification of synaptic metabolites of dynorphin A (1-8) by electrospray ionization and tandem mass spectrometry. Rapid Commun. Mass Spectrom. 12, 1796-1800

79. Lai, S. L., Gu, Y., and Huang, L.-Y. M. (1998) Dynorphin uses a non-opioid 
Dynorphin Peptide Alterations in L-DOPA-induced Dyskinesia

mechanism to potentiate $\mathrm{N}$-methyl-aspartate currents in single rat periaqueductal gray neurons. Neurosci. Lett. 247, 115-118

80. Voorn, P., van de Witte, S. V., Li, K., and Jonker, A. J. (2007) Dynorphin displaces binding at the glycine site of the NMDA receptor in the rat striatum. Neurosci. Lett. 415, 55-58

81. Chen, L., Gu, Y., and Huang, L. Y. (1995) The mechanism of action for the block of NMDA receptor channels by the opioid peptide dynorphin. J. Neurosci. 15, 4602-4611

82. Kanemitsu, Y., Hosoi, M., Zhu, P. J., Weight, F. F., Peoples, R. W., McLaughlin, J. S., and Zhang, L. (2003) Dynorphin A inhibits NMDA receptors through a pH-dependent mechanism. Mol. Cell. Neurosci. 24, 525-537 